\title{
A influência do uso e cobertura da terra nos parâmetros da qualidade da água na bacia hidrográfica do rio Abaúna, em Getúlio Vargas, RS
}

The influence of use and land cover in the water quality parameters in the river basin Abaúna in Getúlio Vargas, RS

\author{
Cassia Figur, Janete Teresinha Reis \\ Universidade Federal da Fronteira Sul \\ kassifigur@hotmail.com \\ Universidade Federal de Santa Maria \\ reis.janete@gmail.com
}

\section{Resumo}

A qualidade da água de uma bacia hidrográfica depende de inúmeros fatores sejam eles naturais ou antrópicos. Desse modo, esta pesquisa objetiva analisar os parâmetros de qualidade da água e a influência do uso e cobertura da terra na bacia hidrográfica do Rio Abaúna,RS. A proposta metodológica possibilitou analisar o meio aquático e o meio terrestre para assim realizar uma integração entre os diferentes usos e cobertura da terra e parâmetros de água. Para isso, utilizou-se da imagem de satélite Landsat 8, para o referido levantamento de uso e cobertura da terra. Os parâmetros da água foram: total de sedimentos em suspensão (TSS), temperatura da água (TEMP.); potencial hidrogeniônico (pH); oxigênio dissolvido(OD), turbidez e coliformes totais. A partir da avaliação integrada dos meios aquático e terrestre, constatou-se que a água da maioria dos pontos de coleta se enquadra nas normas do CONAMA, porém não para o consumo humano e ficou evidente que os usos não estão de acordo com as normas do Código Florestal Federal. Portanto, os usos estão interferindo na qualidade da água alterando as características fisicas, químicas e bacteriológicas. Para a melhoria da qualidade da água de toda bacia hidrográfica é importante executar alternativas de uso e cobertura da terra para a preservação e reposição da mata ciliar.

Palavras-chave: Meio aquático; Meio terrestre; Integração

\section{Abstract}

The water quality of a river basin dependent on numerous factors, whether natural or anthropogenic. Thus, this research aims to analyze the water quality parameters and the influence of land use and land cover in the watershed of Abauna Rio, Brazil. The methodology made it possible to analyze the aquatic and terrestrial environment so as to achieve integration between the different uses and land cover and water parameters. For this, we used the satellite image Landsat 8, for that survey land use and land cover. The water parameters were: total suspended solids (TSS), water temperature (Temp.); hydrogen potential ( $p H)$; dissolved oxygen (DO), turbidity and total coliforms. From the integrated assessment of aquatic and terrestrial environment, it was found that water most collection points falls within the rules of CONAMA, but not for human consumption and it became clear that the uses are not in accordance with the rules of Federal Forest code. Therefore, the uses are interfering in water quality by altering the physical, chemical and bacteriological. For the improvement of the entire watershed water quality it is important to implement the use of alternative and land cover for the preservation and restoration of riparian forest.

Keywords: Aquatic environment; Terrestrial environment; Integration 


\section{Introdução}

A utilização dos recursos naturais, sem o devido planejamento, vem gerando impactos ambientais negativos, em diferentes espaços, tanto urbanos como rurais. A bacia hidrográfica pode ser caracterizada a unidade de planejamento apropriada, por integrar vários elementos como solo, água, vegetação e a fauna que interagem e respondem as interferências, tanto naturais como antrópicas. Para Tucci (1997) a bacia hidrográfica pode ser entendida como área de captação natural da água da precipitação onde os escoamentos convergem para um único ponto de saída, que é o seu exutório.

Pela Política Nacional dos Recursos Hídricos a bacia hidrográfica como unidade de planejamento prevê mecanismos de proteção as nascentes, por meio de leis e decretos que protejam a qualidade da água das mesmas. Aliado a esse fator tem-se a resolução do Conselho Nacional do Meio Ambiente (CONAMA) número 357 , de 17 de março de 2005 que dispõe sobre a classificação dos corpos de água e diretrizes ambientais para o enquadramento dos recursos hídricos, bem como as condições e padrões de lançamento de efluentes que podem ser lançados em bacias hidrográficas (BRASIL, 2005).

Assim, a bacia hidrográfica é o espaço físico de gestão onde diversos elementos naturais interagem em consonância, mas mediante os impactos ambientais negativos da ação antrópica repercutem principalmente na qualidade da água. De acordo com Von Sperling (2005) a qualidade da água está ligada as condições naturais e do uso e ocupação da terra na bacia hidrográfica. Já, para Merten e Minella (2002) a qualidade da água não se restringe apenas na pureza, mas sim as suas características presente pelos diversos usos e ocupações da área.

A partir dos diferentes tipos de uso e cobertura da terra fica evidente a presença da atividade agrícola no município de Getúlio Vargas, mais precisamente na bacia hidrográfica em estudo, uma vez que as lavouras aliadas ao solo exposto assumem grande representatividade. Mas, a presença significativa de mata torna a água de algumas nascentes da bacia com qualidade melhor.

Os crescentes impactos ambientais negativos sobre os recursos hídricos, tanto no meio rural como urbano, pressionam a sociedade em busca de estratégias que visam a melhoria de sua qualidade. A deterioração da qualidade da água alterando as características físicas, químicas e biológicas da água são frutos da alteração dos elementos harmônicos que integram a bacia hidrográfica, tanto no que se refere aos aspectos físicos como antrópicos que agem sobre o meio.

Neste contexto, o total de sedimentos em suspensão (TSS) corresponde a todo material particulado em suspensão na água, que não passa em um filtro de $0,45 \mu \mathrm{m}$. Esses sólidos presentes na água são os orgânicos em suspensão (SOS) e os sólidos inorgânicos em suspensão (SIS). Os sólidos orgânicos, são compostos por fitoplâncton, zooplâncton e matéria orgânica particulada, já os inorgânicos são compostos por partículas minerais, principalmente silte e argila (ESTEVES, 2011).

A presença de sólidos suspensos quanto de sólidos dissolvidos em corpos d'água natural pode ocasionar problemas aos recursos hídricos. Os sólidos podem causar danos aos peixes e à vida aquática, podendo sedimentar no leito dos rios destruindo organismos que fornecem alimentos ou, também, danificar os leitos de desova de peixes. Além disso, podem reter bactérias e resíduos orgânicos no fundo dos rios, promovendo decomposição anaeróbia. Altos teores de sais minerais, particularmente sulfato e cloreto, estão associados à tendência de corrosão em sistemas de distribuição, além de conferir sabor às águas (CETESB, 2009). 
A partir do $\mathrm{pH}$ é possível obter importantes informações sobre processos químicos e biológicos dos corpos de água natural. A escala de análise do $\mathrm{pH}$ vai de 0 a 14, onde o valor 7 de $\mathrm{pH}$ significa neutro, uma água com $\mathrm{pH}$ inferior a 7 é considerado acida e maior do que 7 representa a saturação de base ou alcalinidade (ESTEVES, 1998). Neste sentido, por meio da análise do pH é possível medir a acidez, neutralidade ou alcalinidade de uma solução aquosa.

A importância do $\mathrm{pH}$ se remete diretamente aos ecossistemas naturais, em virtude dos efeitos sobre a fisiologia de diversas espécies. $\mathrm{E}$ indiretamente, os efeitos de $\mathrm{pH}$ podem determinar condições que contribuem para a precipitação de elementos químicos tóxicos como metais pesados; enquanto outras condições podem exercer efeitos sobre as solubilidades de nutrientes (CETESB, 2009). Assim, o pH afeta o metabolismo de várias espécies aquáticas. A Resolução CONAMA n ${ }^{\circ}$ 357/2005 estabelece que para a proteção da vida aquática o pH deve estar entre 6,0 e 9,0 (BRASIL, 2005). Alterações nos valores de pH também podem aumentar o efeito de substâncias químicas que são tóxicas para os organismos aquáticos, os quais os metais pesados.

A temperatura pode ser considerada como a característica mais importante do meio aquático por influenciar vários parâmetros físico-químicos da água, entre eles a tensão superficial e a viscosidade. Já os organismos aquáticos são afetados por temperaturas fora de seus limites de tolerância térmica, pois causam impactos sobre seu crescimento e reprodução (BENETTI; BIDONE, 2002).

A temperatura desempenha um papel importante no meio aquático atuando diretamente numa série de variáveis físico-químicas (CETESB, 2009). Além disso, a variação da temperatura nos recursos hídricos pode ser associada aos fenômenos climáticos, a ação antrópica, por meio do lançamento de efluentes industriais, descargas de torres de resfriamento das usinas térmicas alimentadas ou com combustíveis fósseis (carvão e petróleo) ou por energia nuclear (FELLENBERG, 1980).

A turbidez de uma amostra de água pode ser atribuída em principal às partículas sólidas em suspensão que reduzem a sua transparência e que diminuem a transmissão da luz no meio. Pode ser provocada pela presença de partículas inorgânicas e de detritos orgânicos. O processo natural da erosão em estações chuvosas nas margens dos rios é um exemplo de fenômeno que aumenta a turbidez das águas. Pela proteção física conferida aos microorganismos ao contato direto com os desinfetantes, a turbidez pode reduzir a eficiência da coloração. A frequência da turbidez é maior em águas correntes, devido ao transporte de argila e areia pelas mesmas.

A turbidez, além de representar um requisito estético de qualidade na rede de distribuição, em estudos mais recentes tem demonstrado a presença da turbidez em mananciais que recebem despejos de esgotos domésticos com a presença de organismos patogênicos (GARCIA, 2002). Neste sentido a turbidez, que antes era vista somente pela parte estética, torna-se um requisito sanitário. Portanto, a Portaria MS nº. 2914/2011 do Ministério da Saúde, que trata a turbidez como parâmetro sanitário determina diferentes valores para situações diferentes (BRASIL, 2011).

O parâmetro de oxigênio dissolvido na água é de grande importância, pela necessidade da respiração da maioria dos organismos vivos. De acordo com BRANCO (2003) a quantidade de oxigênio dissolvido, depende da pressão atmosférica e da temperatura da água, ou seja, quanto maior for a pressão, maior a dissolução de oxigênio, e quanto maior a temperatura, menor a dissolução desse gás. E o autor acrescenta que de modo natural existem duas fontes de oxigênio para o sistema aquático, que é a atmosfera e a fotossíntese que são realizados pelos seres vivos. A medida de oxigênio tem muita importância na determinação do estado de saúde do sistema. 
O oxigênio dissolvido na água é uma variável extremamente importante, por medir o estado de saúde do sistema, em casos de pouco oxigênio indica que há algum problema no sistema. De acordo com a CETESB (2009) o OD, pode ser considerado um fator limitante para manutenção da vida aquática e de processos de autodepuração em sistemas aquáticos naturais e estações de tratamento de esgotos. Durante a degradação da matéria orgânica, as bactérias fazem uso do oxigênio nos seus processos respiratórios, podendo vir a causar uma redução de sua concentração no meio. Neste sentido, o valor mínimo de oxigênio dissolvido (OD) para a preservação da vida aquática, estabelecido pela Resolução CONAMA 357/05(2) é de 5,0 mg/L, mas existe variação de tolerância de espécie para espécie (BRASIL, 2005).

Os coliformes fecais e totais consistem em um grupo de bactérias com capacidade de crescer na presença de sais biliares ou com outros compostos ativos de superfície, que apresentam gram-negativos, aeróbicos ou anaeróbicos facultativos, com capacidade de desenvolvimento da lactose com a produção de ácidos, aldeídeos e gás. Neste sentido, Reis (2006) esclarece que os coliformes fecais constituem um grupo de bactérias originárias de trato intestinal humano e de outros animais de sangue quente. Enquanto que os coliformes totais, além de abranger as características dos coliformes fecais, podem ser encontrados também na água e no solo.

Para Bettega et al (2006) os coliformes totais representam um grupo de bactérias que contem bacilos gramnegativos, aeróbios ou anaeróbios facultativos, não formadores de esporos, oxidase-negativa, capazes de crescer na presença de sais biliares ou outros compostos ativos de superfície, com propriedades similares de inibição de crescimento, e que fermentam a lactose com produção de ácidos, aldeídos e gás a $35^{\circ} \mathrm{C}$ em $24-48$ horas. Contudo, esta avaliação vem tendo um papel destacado, devido a grande variedade de microrganismos patogênicos, em sua maioria de origem fecal, que pode estar presentes na água.

Neste intuito, o conhecimento do uso e cobertura da terra é um requisito importante no planejamento integral de uma bacia hidrográfica, conforme recomenda Assad e Sano (1998), pois, o ambiente aquático por ser sensível a qualquer interferência que ocorre na bacia, altera as características naturais da água. De acordo com Pereira Filho (2000) o homem é o principal responsável da modificação dos ambientes e sua atividade determina as condições de uso de vertentes. Ao complementar destaca os autores Likes e Bormann (1974) que abordam sobre as ligações entre os ecossistemas aquático e terrestre, salientando que "a chave do gerenciamento correto do ecossistema aquático é o gerenciamento correto do ecossistema terrestre" (PEREIRA FILHO, 2000, p.17).

Considerando que a bacia hidrográfica deve ser analisada de forma integrada, o presente trabalho visa analisar a influência do uso e cobertura da terra nos parâmetros de qualidade da água na bacia hidrográfica do Rio Abaúna, tendo como auxílio técnicas de sensoriamento remoto e análise de água. Assim, mais especificamente, realizar-se-á o levantamento dos diferentes tipos de uso e cobertura da terra na bacia hidrográfica, bem como será avaliado alguns parâmetros de qualidade da água.

Por último, será realizado a análise integrada entre os diferentes usos e cobertura da terra e parâmetros de qualidade, apontando os principais usos que interferem na qualidade da água. A partir disso, propor alternativas para tomada de decisão dos órgãos públicos, como sugestão de preservação da bacia hidrográfica do Rio Abaúna/ RS. 


\section{Metodologia}

A presente pesquisa considera o impacto que o uso e cobertura da terra exercem na bacia hidrográfica e sua influência na qualidade da água visando à integração do meio aquático e terrestre, conforme segue as etapas apresentadas na figura 1.

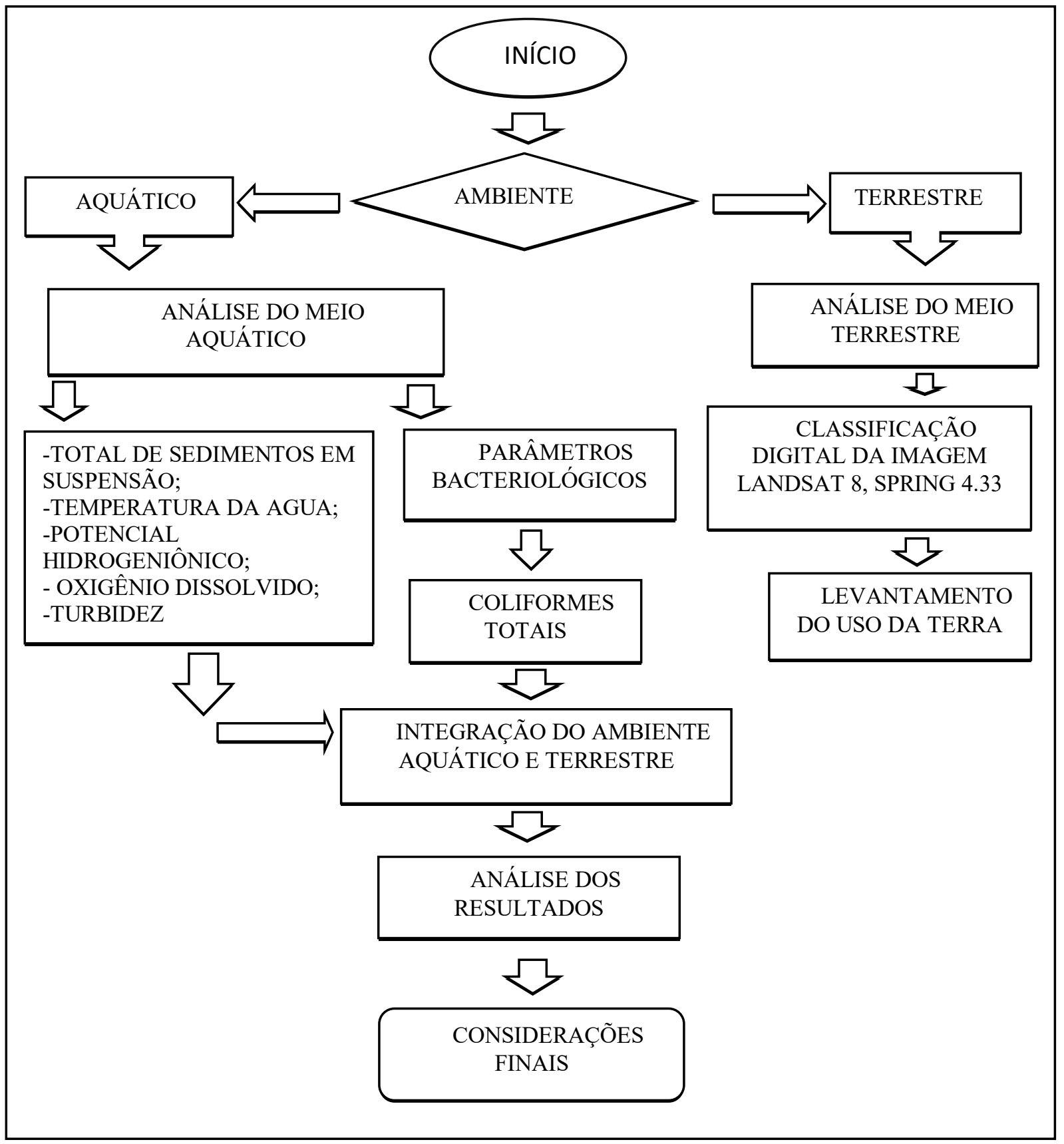

Figura 1 - Etapas metodológicas desenvolvidas no trabalho

Org: FIGUR, C.;REIS, J.T., 2016

Inicialmente realizou-se o levantamento bibliográfico por meio da consulta a matrizes teóricas para aprofundar a temática. Posteriormente, um trabalho a campo para identificação da área de estudo acompanhada do mapeamento básico para determinar os pontos de coleta da água, além de identificar a realidade a campo. Em seguida, elaborou-se o mapa de uso e cobertura da terra de toda bacia hidrográfica. 
Para definir os pontos de coleta e análise da água na bacia hidrográfica alguns critérios foram estipulados, como: acesso ao ponto amostral, áreas protegidas por vegetação ciliar (caso houver), locais sem preservação de vegetação ciliar.

Foi realizada a coleta de água em nove pontos da bacia em estudo com o objetivo de analisar a água das áreas de contribuição de toda bacia hidrográfica, oriundas do meio rural e meio urbano, tendo em vista a interferência que os usos exercem sobre o ambiente aquático. Portanto, tem-se um uso da terra que exerce forte pressão sobre o meio aquático que consiste o meio urbano onde há forte concentração populacional aliado a infraestrutura correspondente.

A coleta de água realizada na foz inserida na zona urbana, teve como meta averiguar o aumento de coliformes totais na água, em virtude do lançamento de esgoto da área urbana. Neste sentido, os parâmetros analisados foram: potencial hidrogenionico $(\mathrm{pH})$, oxigênio dissolvido (OD), temperatura da água, temperatura ambiente, turbidez e coliformes totais. As coletas de água foram analisadas in loco e no laboratório. As que puderem ser analisadas a campo foram: oxigênio dissolvido, temperatura da água e temperatura ambiente, as demais, exceto os de coliformes totais que foi realizado em laboratório particular de Getúlio Vargas-RS, as demais foram analisadas no laboratório de Química da Universidade Federal da Fronteira Sul, Campus Erechim-RS.

\subsection{Ambiente Aquático}

\subsubsection{Parâmetros de análise de água}

Para a coleta de água foram utilizadas garrafas plásticas com capacidade de $500 \mathrm{ml}$. As garrafas foram devidamente identificadas de acordo com cada ponto de coleta, refrigeradas e armazenadas para posterior análise. Porém, para a análise bacteriológica (coliformes totais) foram utilizadas recipientes especiais do laboratório, pois precisam ser vidraçarias especiais e esterilizadas.

\subsubsection{Potencial hidrogeniônico $(\mathrm{pH})$}

A análise do $\mathrm{pH}$ foi realizada no laboratório de química da Universidade Federal da Fronteira Sul, com auxílio do pHmetro. Para tanto, inicialmente o aparelho foi calibrado e após, introduzida base de metal do pHmetro na água fornecendo a leitura dos índices de $\mathrm{pH}$ da água.

\subsubsection{Oxigênio dissolvido (OD) e temperatura ambiente e da água}

Estas análises realizadas a campo com auxílio do aparelho Oxímetro que ao calibrar automaticamente foi mergulhada a base na água fornecendo o índice de oxigênio dissolvido e de temperatura da água. A temperatura ambiente também foi fornecida pelo aparelho, porém, antes de mergulhá-lo na água.

\subsubsection{Coliformes totais}

Para a análise de coliformes totais, que foi feita em laboratório particular, no município de Getúlio Vargas/RS, a metodologia requer cuidados na coleta da água porque não pode haver presença de ar no recipiente. Para tanto, exigiu o mergulho integral do frasco de vidro esterilizado na água para evitar a presença de ar, uma vez que exige total ausência de ar. Seguindo as normas técnicas foi acondicionado em caixa de isopor e conduzida até o laboratório de análise. 
A técnica utilizada foi da fermentação em tubos múltiplos e o número a ser considerado é o mais provável de coliformes totais. Assim, inicialmente verifica-se a presença ou não de coliformes totais. Neste processo, somente constata-se se há presença ou não coliformes na água.

\subsection{1 .4 Total de sedimentos em suspensão}

Para a análise do TSS foram adotados alguns procedimentos conforme a metodologia de Agudo et al (1988) que consiste na secagem dos filtros em estufa de esterilização universal, a uma temperatura de aproximadamente $60^{\circ} \mathrm{C}$ por um período de 24 horas antes da filtragem da água.

Em próximo momento realizou-se a pesagem dos filtros em uma balança de precisão, para obter o valor referente ao peso inicial do filtro, logo após foi filtrada a amostra de água contendo $100 \mathrm{ml}$ e o filtro foi novamente para a estufa por mais 24 horas. Após este período efetuou-se novamente a pesagem do filtro para saber o valor do peso final do filtro. Ao concluir estas etapas, iniciou-se a etapa do cálculo com a aplicação da equação elaborada por Agudo et al (1988 apud REIS, 2006):

$$
\mathrm{TSS}=\frac{\mathrm{PFG}-\mathrm{PIG} \times 1000}{\text { VOL. }(\mathrm{L})}
$$

Onde:

TSS $=$ total de sedimentos em suspensão

$\mathrm{PFG}=$ peso final em gramas

$\mathrm{PIG}=$ peso inicial em gramas

VOL. = volume

\subsection{Ambiente Terrestre}

Para a elaboração do mapa de uso e cobertura da terra, inicialmente realizou-se a coleta da Imagem Landsat 8, do dia 6 de janeiro de 2016, com o critério da menor presença ou ausência de nuvens, a que melhor identificou os diferentes tipos de uso e cobertura da terra associada a proximidade com os dias de coleta de água. A imagem adquirida foi no site do Serviço de Levantamento Geológico Americano (USGS, 2016). Já, a base cartográfica utilizada foi extraída no IBGE, por meio do site do Instituto Brasileiro de Geografia Estatística (IBGE, 2010).

O mapa de uso e cobertura da terra foi elaborado no programa do ArCGis 10.2.1. Após importação da imagem de satélite já previamente georreferenciada realizou-se a coleta de amostras de cada classe de uso. Posteriormente realizou-se a classificação supervisionada, no qual coletou-se amostras e aplicou-se para toda a imagem da área de estudo. Assim, as classes que foram identificadas na imagem junto à área de estudo foram as seguintes:

1) Agricultura: áreas destinadas ao cultivo temporário; 
2) Solo exposto; área descoberta ou seja, sem a proteção por vegetação ou cultura.

3) Floresta: vegetação densa;

4) Campo: vegetação arbustiva, gramado;

5) Água;

6) Área urbana.

A base de dados e o processamento dos shapes foram gerados no Quantum Gis 2.8.1, tendo em vista a facilidade da obtenção e disponibilidade dos dados neste programa, porém a classificação das imagens bem como o Layout foi realizado no arGis 10.2.1. Este por apresentar uma melhor classificação dos usos e facilidade com o layout.

\section{Resultados e discussões}

A análise dos resultados está organizada em três partes. Primeiramente, realizou-se a análise dos parâmetros de qualidade das águas coletadas, seguida da análise do uso e cobertura da terra, após influência dos usos na qualidade da água da bacia hidrográfica do Rio Abaúna, em Getúlio Vargas- RS.

\subsection{Análise dos parâmetros da qualidade da água}

A caracterização da água é determinada por diversos parâmetros, os quais representam suas características químicas, físicas e biológicas. Tais parâmetros indicam a qualidade da água e quando alcançam determinados valores superiores aos estabelecidos, para usos, determinam a constituição de impurezas.

Observa-se na figura 2 que nos pontos das coletas, o maior valor de oxigênio dissolvido é o ponto 3 com $7,91 \mathrm{mg} / 1$, e o menor no ponto 7 com o valor de $5,86 \mathrm{mg} / 1$.

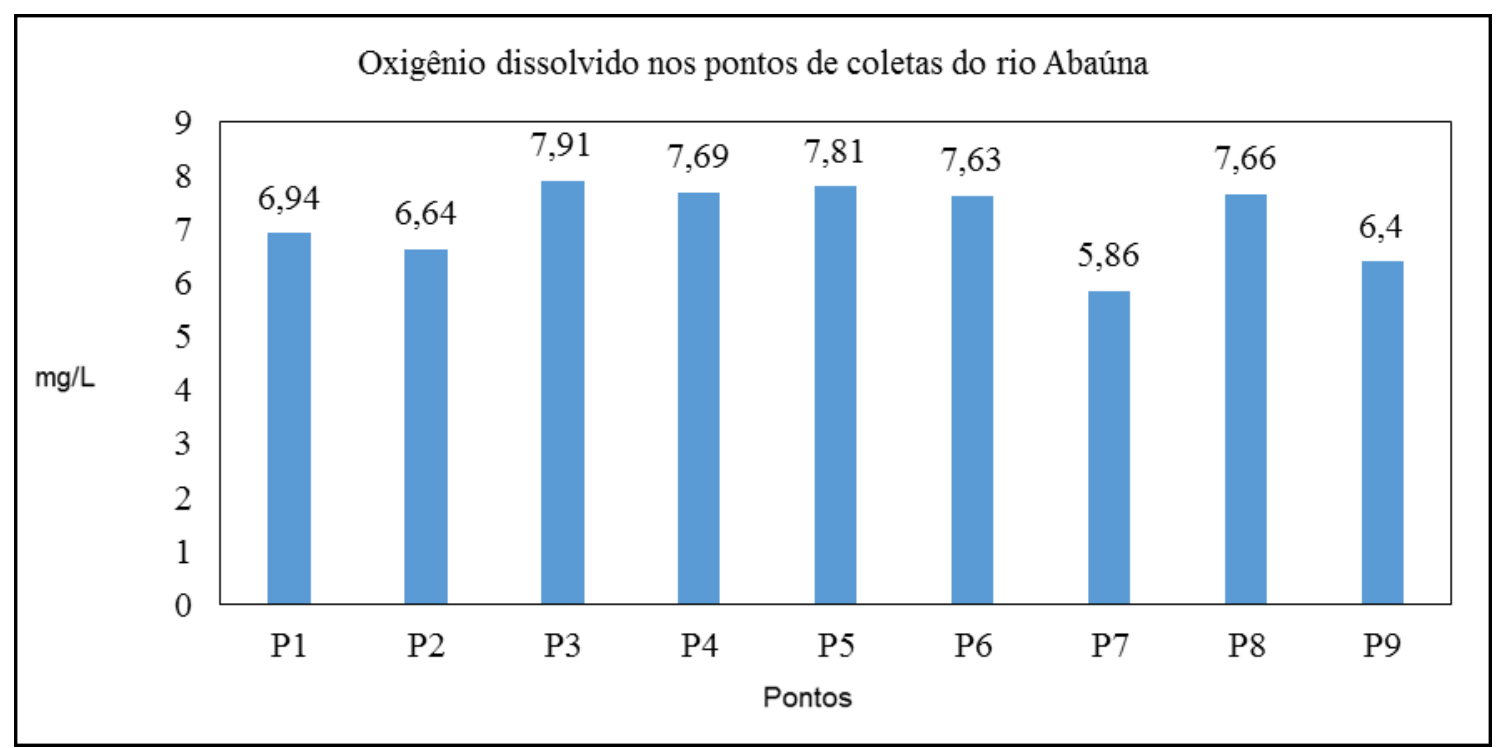

Figura 2 - Variação do Oxigênio Dissolvido na área de estudo

Fonte: Trabalho de campo, Getúlio Vargas-2016 (20.05.16) Org: FIGUR, Cássia.

Segundo o BRASIL (2005), pela resolução 357, seção II das águas, estabelece as seguintes condições e padrões: o oxigênio dissolvido (OD), em qualquer amostra não pode ser inferior a $6 \mathrm{mg} / \mathrm{l}$. Porém, os resultados mostraram que os valores de oxigênio variaram de 5,86 mg/1 e 7,91 mg/l. A média aproximada é de 6,88 mg/l. Nesse sentido, observa-se 
que os valores dos pontos de coletas estão dentro das normas e padrões do CONAMA, indicando características naturais, exceto o ponto 7 que apresentou o valor de 5,86mg/l, devido ser uma nascente localizada em área de banhado com água parada e visivelmente turva.

A faixa de variação do $\mathrm{pH}$ foi de 6,4 à 7,43 nos pontos de coletas (Figura 3), com uma média aproximada de 7 . Observa-se também que nos pontos de coletas encontra-se águas ácidas com pH menor que 7, que são nos pontos 1, 7 e 9 e nos pontos 2, 3 ,4, 5, 6 e 8 são águas básicas. Porém, segundo o BRASIL (2005), resolução 357, seção II das águas, o padrão de pH é de 6 à 9 , assim os resultados das coletas são considerados satisfatórios.

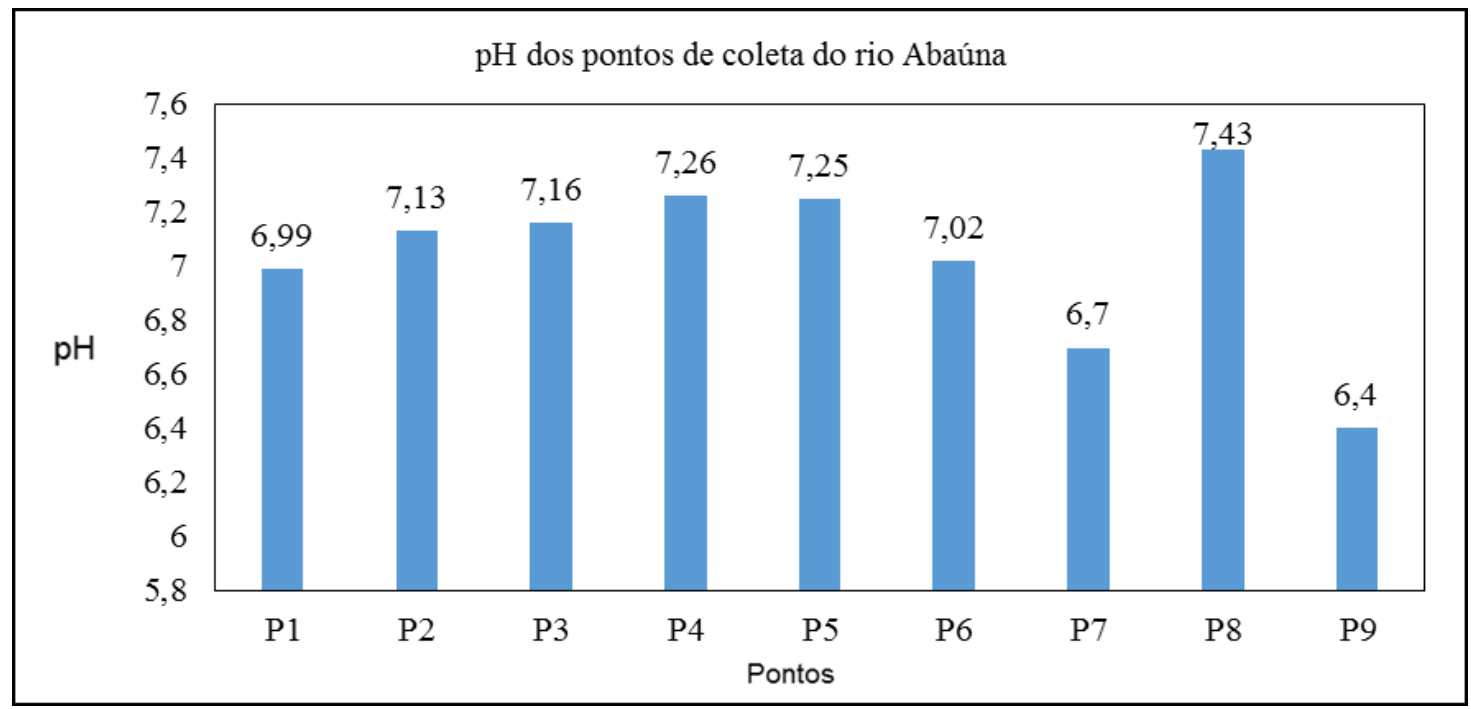

Figura 3 - Variação de pH na área de estudo

Fonte - Trabalho de campo, Getúlio Vargas-2016 (20.05.16) Org: FIGUR, Cássia

Na figura 4, observa-se uma variação de 0.54 NTU à 43 NTU, considerando que todos os pontos a partir do 2 são nascentes do Rio Abaúna e o ponto 1 a foz. A média de turbidez ficou com valor aproximado de 14 NTU.

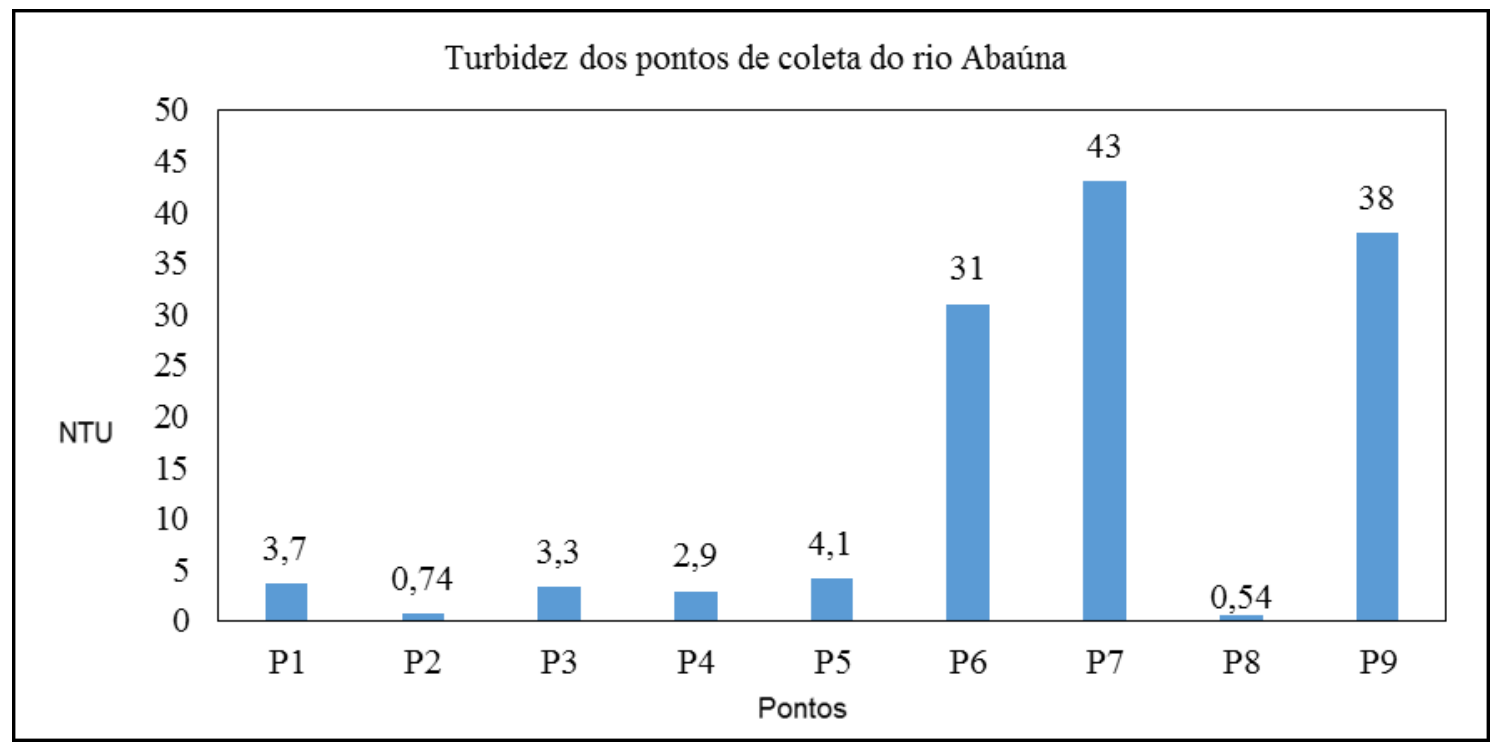

Figura 4 - Faixa de variação da Turbidez na área de estudo

Fonte - Trabalho de campo, Getúlio Vargas-2016 (20.05.16) Org: FIGUR, Cássia 
Segundo o BRASIL (2005), resolução 357, seção II das águas, a turbidez até 40 unidades nefelométricas está dentro das normas para ser inserida nas condições de qualidade das águas. As nascentes 6, 7 e 9 são as que possuem maior valor de turbidez. Porém, somente o ponto 7, com o valor de 43 NTU, não se enquadra dentro das normas do CONAMA, em virtude da ação antrópica oriunda do desmatamento.

$\mathrm{Na}$ figura 5, observa-se a faixa da variação da temperatura dos pontos de coletas do Rio Abaúna, que é aproximadamente em torno de $14^{\circ} \mathrm{C}$. O ponto 2 apresentou a temperatura maior e o ponto 1 , a menor. As coletas de água foram feitas no mês de maio, no outono, assim podendo ter ligações diretas com os valores de temperatura. A faixa de variação ficou com em $13,4^{\circ} \mathrm{C}$ e $15,5^{\circ} \mathrm{C}$

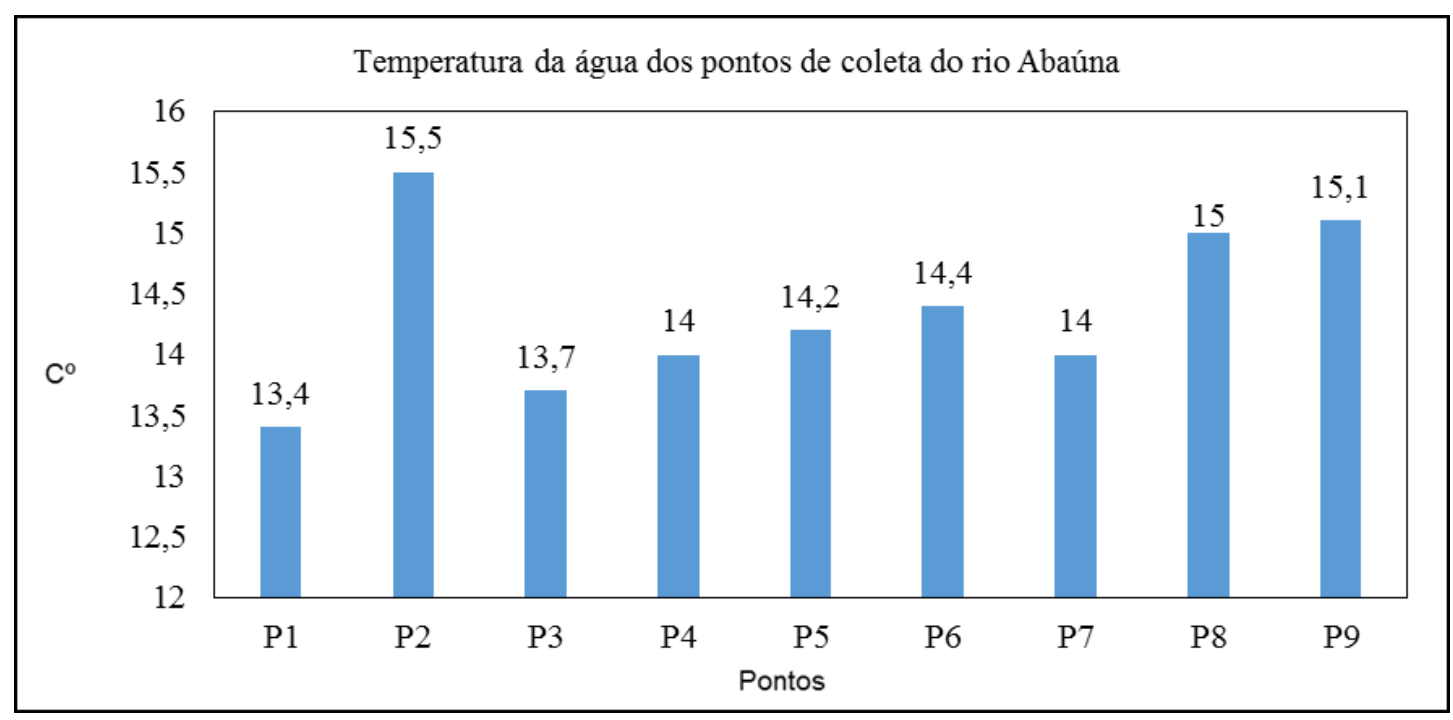

Figura 5 - Temperatura da água na área de estudo

Fonte: Trabalho de campo, Getúlio Vargas-2016 (20.05.16] Org: FIGUR, Cássia

A faixa de variação do total de sedimentos dissolvidos nos pontos de coleta ficou entre $10 \mathrm{mg} / \mathrm{L} \mathrm{e} 710 \mathrm{mg} / \mathrm{L}$, perfazendo uma média de $292 \mathrm{mg} / \mathrm{l}$ (Figura 6). Porém, considera-se uma variação muito grande tendo em vista que o ponto 7 apresentou um elevado valor de sedimentos em suspensão, destacando-se também os pontos 9 e 6 .

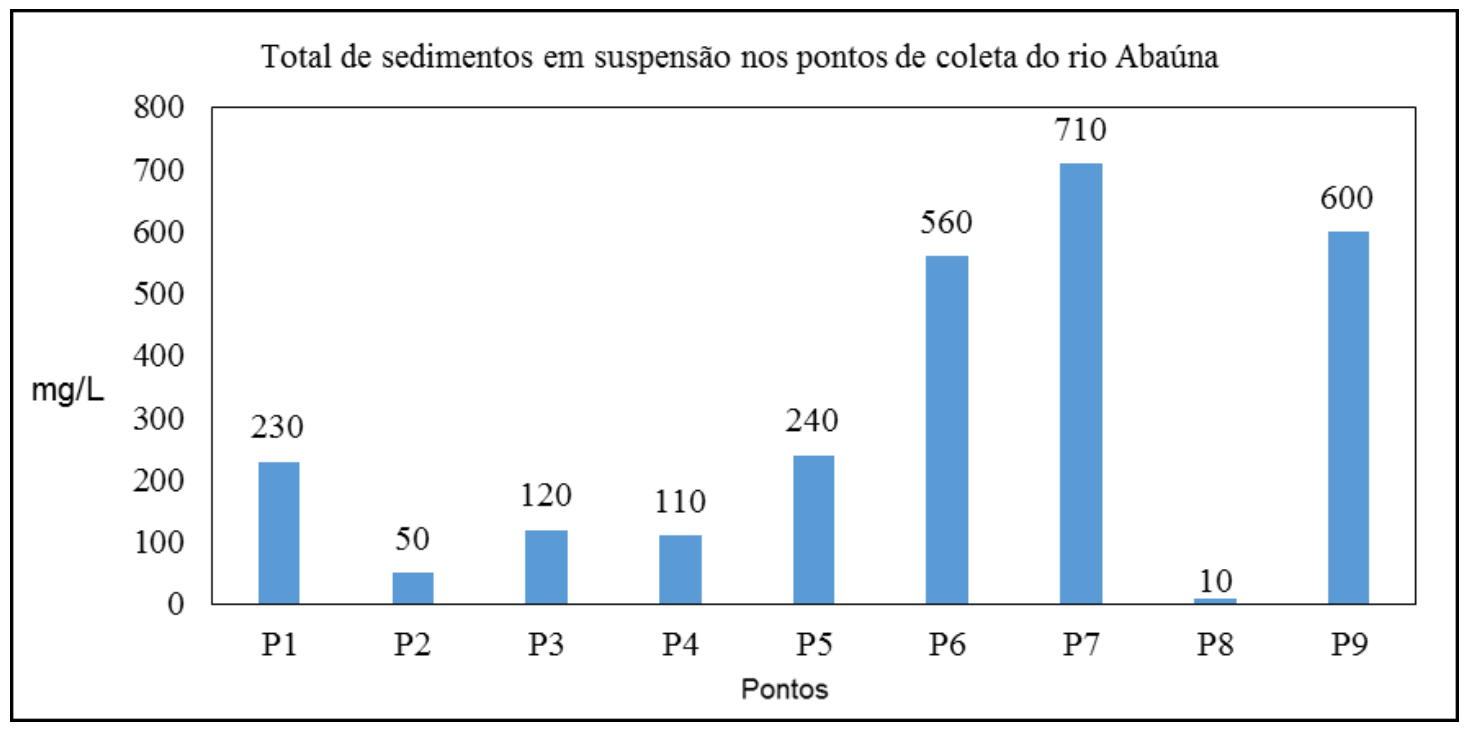

Figura 6 - Total de sedimentos em suspensão na área de estudo

Fonte - Trabalho de campo, Getúlio Vargas-2016 (20.05.16) Org: FIGUR, Cássia 
Para Tundisi e Tundisi (2008), o volume de material transportado pelos rios está ligado ao grau de cobertura vegetal e de desmatamento, das bacias hidrográficas. Outro importante ponto a ser considerado na análise de TSS, é a precipitação pluvial.

\subsection{Uso e cobertura da terra na bacia hidrográfica}

Os dados do mapeamento do uso e cobertura da terra da bacia hidrográfica do Rio Abaúna, resultaram a partir partir da obtenção das classes de uso e cobertura da terra foi possivel extrair seis classes e suas áreas apresentadas em $\mathrm{km}^{2}$ de acordo com cada uso e os seus referidos percentuais (Tabela 1).

Tabela 1 - Classes de usos e cobertura da terra e percentuais na bacia hidrográfica do Rio Abaúna, RS - 2016

\begin{tabular}{l|c|c}
\hline Classes & Área $\left(\mathbf{k m}^{\mathbf{2}} \mathbf{)}\right.$ & $\mathbf{\%}$ \\
\hline Floresta & 25,34 & 44,61 \\
\hline Campos & 3,64 & 6,41 \\
\hline Água & 0,072 & 0,12 \\
\hline Solo exposto & 3,2 & 5,63 \\
\hline Lavoura & 15,35 & 27,02 \\
\hline Área urbana & 9,2 & 16,21 \\
\hline Área Total & 56,802 & 100 \\
\hline
\end{tabular}

Org: FIGUR, Cássia

No mapa de uso e cobertura da terra (Figura 7) e na Tabela 1 constata-se que a área total da bacia hidrográfica do Rio Abaúna abrange 56,80 $\mathrm{km}^{2}$. Destes, as florestas ocupavam 25,34 $\mathrm{km}^{2}$ em janeiro de 2016 assumindo o maior percentual com 44,61\% caracterizado como um percentual significativo e importante para a manutenção da fauna ou biodiversidade. Em seguida, as lavouras ocorrem em 15,35 $\mathrm{km}^{2}$ perfazendo 27,02\% da área de estudo.

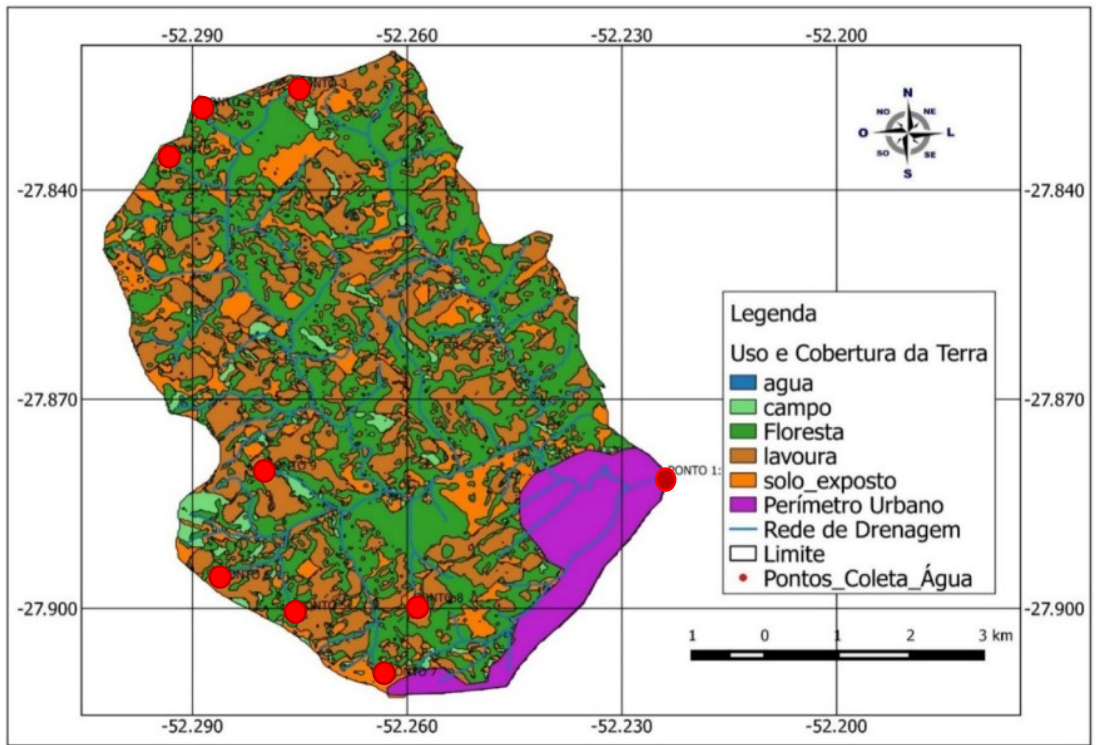

Figura 7 - Mapa de uso e cobertura da terra na bacia hidrográfica do rio Abaúna, em Getúlio Vargas/RS Org: Figur C., Reis J. T 
Cabe destacar que o solo exposto, provavelmente, também corresponde a lavoura, tendo em vista que o milho plantado e recém colhido é um produto agrícola cultivado na área pelo produtor rural. Em caso do solo exposto também ser lavoura, somaria um total de $18,55 \mathrm{~km}^{2}$. Neste sentido, a atividade agrícola que é o segundo uso mais significativo na bacia hidrográfica teria um percentual ainda maior. Por outro lado a água e os campos são os usos menos presentes na área de estudo.

De acordo com a figura 7 constata-se que a maior parte da floresta encontra-se no entorno dos cursos de água, assim como os campos, embora este último encontra-se em percentual pouco expressivo. A floresta praticamente pode ser encontrada de forma esparsa acompanhando os cursos de água, enquanto que a lavoura e solo exposto são mais representativos a oeste da bacia hidrográfica, seguindo até a foz. A floresta é mais expressiva a leste.

As áreas de maior declividade também são pouco preservadas por floresta e apresentam áreas de lavouras, conforme verificado a campo. Assim, verifica-se que a concentração das áreas agrícolas encontra-se nos três cursos, mas principalmente no alto e médio curso dos rios, enquanto que no baixo curso, encontra-se a área urbana.

Seguindo as normas do Código Florestal Federal as nascentes devem conter ao menos 50 metros de floresta no seu entorno. Portanto, esta norma muitas vezes não é contemplada na integra, devido ao fato da presença de vegetação exótica ao invés da vegetação nativa. Salienta-se que a preservação de floresta nativa é muito importante, pois, além de servir como filtro da água protegem o solo do impacto direto da chuva e da ação erosiva, além da proteção a fauna.

\subsection{Influência do uso e cobertura da terra na qualidade da água da Bacia Hidrográfica do Rio Abaúna}

Ao analisar o uso e a cobertura da terra que influência na qualidade da água de toda bacia hidrográfica do Rio Abaúna, tem-se como referência o ponto de coleta de água da foz. Assim, deve-se levar em consideração as classes de usos e cobertura encontradas e integrar com as análises de água efetuados.

Os usos e cobertura da terra registrados foram: campo, floresta, lavoura, solo exposto, água e área urbana. Destes, os que mais interferiram na determinação da qualidade da água foram as florestas, com 44, 61\%, seguida da lavoura, com $27,02 \%$.

O curso principal do rio, percorre um trajeto significativo da área urbana, porém ao confrontar com o oxigênio dissolvido, constata-se que atendeu as normas do Conama com 6,94mg/l. Quanto ao pH registrou-se 6,99 considerado satisfatório. A partir da análise da turbidez registrou-se 3,7 na foz considerado dentro das normas de qualidade das águas. Já temperatura não alterou muito em relação a do ambiente em torno de $13,3^{\circ} \mathrm{C}$. Neste ponto registrou-se a presença de coliformes totais, sendo que para o consumo humano deve ter total ausência de coliformes totais. O total de sedimentos em suspensão permaneceu em torno de $230 \mathrm{mg} / \mathrm{L}$. Portanto, o ponto da foz atendeu aos critérios estabelecidos pelo CONAMA, exceto quanto aos coliformes totais.

Ao integrar as análises de água e os usos da bacia hidrográfica, percebe-se que a presença de floresta com $44,61 \%$ auxilia para que a água da bacia hidrográfica contenha valores que estão de acordo com os padrões do CONAMA. A floresta auxilia na contenção de materiais sólidos e exerce papel de filtro e auxilia na retenção do solo para dentro do leito fluvial. Em contrapartida, a lavoura e solo exposto que também são expressivos na área de estudo, são facilitadores para o aumento dos sedimentos em suspensão, que pode ser observado nas nascentes onde apresentamse em sua maior proporção. Já, a área urbana vem a contribuir na presença de coliformes totais, por haver uma 
concentração de população e a maioria não possui o esgoto tratado de forma adequada, embora contenha pequeno percentual de vegetação no seu entorno.

Os campos que também exercem papel de conter sedimentos e auxiliar como filtro da água, representam pequeno percentual, $6,4 \%$ correspondendo a $3,64 \mathrm{~km}^{2}$. No entanto, constatou-se que a bacia hidrográfica apresenta, em parte, preservação das florestas, em determinados pontos, mas não segue fielmente as normas do Código Florestal Federal.

\section{Considerações finais}

O presente trabalho objetivou analisar a qualidade da água e a influência do uso e cobertura da terra nas nascentes da Bacia Hidrográfica do Rio Abaúna, RS. Assim, teve-se como base a análise do meio aquático, por meio de coletas de água em alguns pontos de nascentes e na foz e o meio terrestre a partir da imagem de satélite Landsat que possibilitou averiguar a influência dos usos e cobertura da terra na qualidade da água de forma integrada.

O mapeamento forneceu informações e dados importantes sobre as atividades antrópicas que interferem na qualidade da água das nascentes do Rio Abaúna que poderá contribuir para uma gestão mais eficaz e melhor gerenciamento dos meios terrestre e aquático, em benefício da preservação da mata ciliar.

Com a presença significativa de florestas ao entorno de algumas nascentes, a qualidade da água está mantida, ficando dentro das normas do CONAMA. No entanto, nem todos os pontos de coleta estão protegidos com vegetação nativa conforme as exigências. A presença de lavoura e solo exposto na área de estudo permitiu a presença de sedimentos em suspensão que trouxe alterações na qualidade da água, assim como a área urbana na interferência da presença de coliformes totais.

A realização do presente estudo foi proposto no intuito de melhorar a gestão da bacia hidrográfica propondo alternativas para sua recuperação. Embora a qualidade da água pode ser considerada boa, planejar o ambiente requer estudos que considerem os aspectos relacionados, tanto à água como ao uso e ocupação da terra para que as áreas continuem preservadas e ocorra a adequação das não preservadas com mata ciliar.

Para tanto, ações de preservação da mata ciliar e conscientização são de extrema importância para o rio Abaúna para a população local, por meio de visitas. Assim, o planejamento integrado com conhecimento técnico, programas educativos e valoração ambiental devem ser implementadas.

\section{Referências}

ASSAD, E. D. e SANO, E.E. Sistemas e informações geográficas - Aplicações na agricultura 2ed Ver. E ampl. Brasília: EMBRAPA/ SPI EMBRAPACEPAC,1998.

BENETTI, A.; BIDONE, F. O Meio ambiente e os recursos hídricos. In: TUCCI, C. E. M. (Org.) Hidrologia: ciência e aplicação. 3. ed. Porto Alegre: Ed. da UFRGS/ABRH, 2002. cap. 22, p. 849-875. (Coleção ABRH de Recursos Hídricos; v.4).

BETTEGA, J.M.P.R et al. Métodos analíticos no controle microbiológico de agua para consumo humano. Cienc. agrotec. [online]. 2006, vol.30, n.5, pp.950-954. ISSN 1413-7054.

BRANCO, S. M. Água: Origem, Uso e Preservação. $2^{\circ}$ Ed. São Paulo. Moderna. 2003

BRASIL. Ministério do Meio Ambiente - MMA. Resolução CONAMA no 357/2005.Disponívelem:www.mma. gov.br/port/conama/res/res05/res35705.pdf. Acesso em: 15 maio. 2016. 
BRASIL. Ministério da Saúde - Portaria MS nํ. 2914/2011. Disponível em: http://bvsms.saude.gov.br/bvs/ saudelegis/gm/2011/prt2914_12_12_2011.html. Acesso em: 16 mar. 2017.

CETESB - Companhia Ambiental do Estado de São Paulo. Qualidade das águas interiores no estado de São Paulo: significado ambiental e sanitário das variáveis de qualidade das águas e dos sedimentos e metodologias analíticas e de amostragem. São Paulo: CETESB, 2009. 44 p. (série relatórios). Disponível em: <http://www.cetesb.sp.gov.br/userfiles/file/agua/aguas-superficiais/variaveis.pdf >. Acesso em: 05 maio 2016.

GARCIA, T.V. Remoção de algas através da eletroflotação - tratamento eletrolítico seguido de filtração diretano tratamento de água de abastecimento. 2002. 97 f. Dissertação de Mestrado em Engenharia Ambiental. Centro Tecnológico da Universidade Federal de Santa Catarina. Florianópolis- SC, 2002. Disponível em: https://repositorio.ufsc.br/bitstream/handle/123456789/83184/184682.pdf?sequence=1. Acesso em: mar. 2017.

IBGE. Instituto Brasileiro de Geografia e Estatística. 2010. Disponível em: <https://www.google.com.br/webh p? sourceid=chromeinstant\&ion=1\&espv=2\&ie=UTF-8\#q=ibge .> Acessado em: 06 de abril de 2016.

ESTEVES, F. A. Fundamentos de limnologia. 3aㅗ ed. Rio de Janeiro: Interciência, 2011.

ESTEVES, F. A. Fundamentos da Limnologia. 2ª ed. Rio de Janeiro: Interciência,1998.

FELLENBERG, G. Introdução aos problemas da poluição ambiental. São Paulo: EPU/EDUSP, 1980.

MERTEN, G. H.; MINELLA, J. P. Qualidade da água em bacias hidrográficas rurais: um desafio atual para a sobrevivência futura. Agroecologia. e Desenvolvimento Rural Sustentável. Porto Alegre, v.3, n.4, out/dez 2002.

PEREIRA Filho, W. Influências dos diferentes tipos de uso da Terra em bacias Hidrográficas sobre sistemas Aquáticos da margem esquerda do reservatório de Tucuruí- Para. 2000.f.138. Tese (Doutorado em Geografia). Universidade de São Paulo, São Paulo, 2000.

REIS, J. T. Influência do Uso e Ocupação da Terra no Ecossistema Aquático da Sub-Bacia hidrográfica do Arroio Cadena, em Santa Maria - RS. 2006. 110 f. Dissertação de Mestrado em Engenharia Rural Centro de Ciências Rurais - Programa de Pós-Graduação em Geomática, Universidade Federal de Santa Maria, Santa Maria, 2006. Disponível em: http://cascavel.ufsm.br/tede/tde_arquivos/21/TDE-2007-0824T135654Z-787/Publico/janete.pdf. Acesso em: 18 nov. 2015

TUCCI, C. E. M. 1997. Hidrologia: ciência e aplicação. 2.ed. Porto Alegre: ABRH/Editora da UFRGS, 1997.

TUNDISI, J. G.; TUNDISI, T. M. Limnologia. São Paulo: Oficina de Textos, 2008. Disponível em: https://books. google.com.br/books?isbn=8579751012. Acesso em: 09 Out. 2016.

VON SPERLING, M. Noções de qualidade das águas. In: Introdução à qualidade das águas e ao tratamento de esgotos. 3ํo ed. Belo Horizonte: Departamento de Engenharia Sanitária e Ambiental, UFMG, 2005. 